\title{
Endoprosthetic Replacement of the Distal Femur for Giant Cell Tumor: A Case Report
}

\section{Khaled Khelil*, Saber Saadi, Abderrazek Rafrafi, Khalil Amri, Rami Ben Arab, Talel Znagui and Lotfi Nouisri}

Department of Orthopedics, The Main Military Hospital of Instruction of Tunis,

Tunis, Tunisia

*Corresponding Author: Khaled Khelil, Department of Orthopedics, The Main Military Hospital of Instruction of Tunis, Tunis, Tunisia.

DOI: 10.31080/ASMS.2020.04.0698
Received: June 20, 2020

Published: July 28, 2020

(C) All rights are reserved by Khaled Khelil., et al.

\section{Abstract}

Giant cell tumor occur mainly in young adults and account for $5 \%$ of all primary tumors of bone. It generally affect the metaphysoepiphyseal region of long bones, as well as less often flat bones. Distal femur and proximal tibia are the most common sites followed by the distal radius. Though this tumor is classified as benign, it is characterized by a high potential of local aggressiveness, a high risk of recurrence, a risk of metastasis and malignant degeneration.

Although these tumors are fully studied, their treatment remains a subject of debate, in fact the challenge is to resect the entire tumor while maintaining the proper functioning of the affected limb. Currently, with the technical advances in the prosthetic field, the use of massive prosthesis after resection showed it superiority compared to the other methods of reconstruction. In this presentation, we aimed to report the case of a patient with distal femoral giant cell tumor treated by en bloc resection and reconstruction by a hinge massive prosthesis with good functional outcome.

Keywords: Giant Cell Tumor (GCT); Metaphysoepiphyseal Region; Distal Femur

\section{Introduction}

Giant cell tumor (GCT) occur mainly in young adults and account for $5 \%$ of all primary tumors of bone. It generally affect the metaphysoepiphyseal region of long bones, as well as less often flat bones. It most frequently occur in the distal femur and the proximal tibia [1]. It histogenesis is still uncertain. Though not a malignant neoplasm, it often exhibits locally aggressive behavior and can metastasize to the lungs in $2 \%$ to $9 \%$ of cases [2].

The available surgical options range from curettage to wide resection with suitable reconstruction. Wide resection is reserved for aggressive, recurrent, and extensive tumors. Among the many reconstruction methods, prosthetic replacement after tumor resection has been widely used because it has the advantages of complete resection, low postoperative recurrence rate and high rate of excellent short-term postoperative limb function [3]. In this presentation, we aimed to report the case of a patient with distal femoral giant cell tumor treated by en bloc resection and reconstruction by a hinge massive prosthesis illustrated by a review of the recent literature.

\section{Patient and Observation}

A 32-year-old woman presented in our out-patient department of Orthopaedics with a chief complaint of progressive left knee pain since 2 months. There was no history of trauma to the affected knee or leg. She did not give history of fever nor alteration of the general state.

Physical examination revealed exquisite pain in lower extremity of femur, a diffuse swelling and limited mobility of the knee. 
Anteroposterior and lateral radiographs of the left knee demonstrated an osteolytic lesion in the epiphysis involving the metaphysis and extending in the subchondral bone of the distal femur (Figure 1).
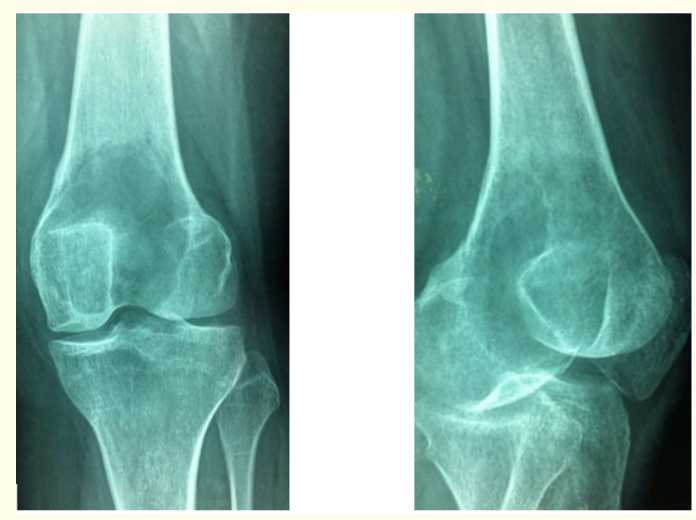

Figure 1: Anteroposterior and lateral left knee Radiographs: demonstrate Osteolytic lesion in the distal femoral metaphysis, with extension into the epiphysis.

Magnetic resonance imaging (MRI) of left knee showed cortical destruction and extra osseous extend of the tumor with involvement of joint space without involvement of neurovascular structures around the knee (Figure 2).

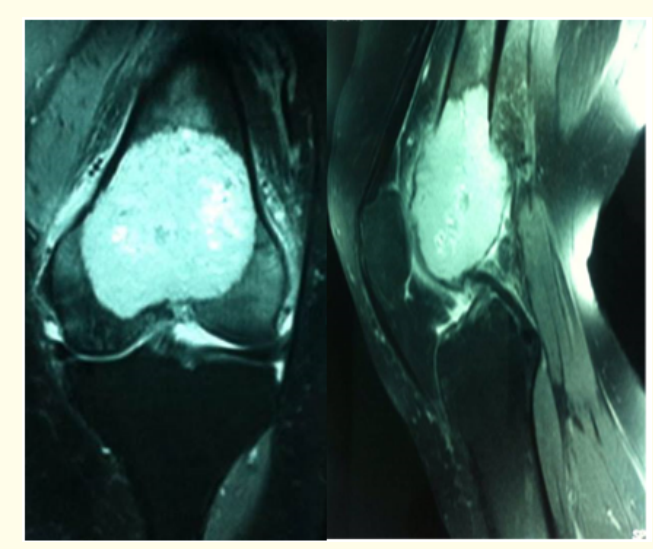

Figure 2: Frontal and sagittal MRI sections of left knee.

An open biopsy was taken from the swelling which confirmed the diagnosis of GCT.
The tumor was in stage 2 according to Enneking system for benign tumors.

In the context of the tumor extension report, thoraco-abdomino-pelvic CT scan and bone scintigraphy showed no metastasis.

The size of the tumor resection was estimated from radiographic and MRI measurements. The carcinological resection carries $16 \mathrm{~cm}$ corresponding to a size of the tumor and $2 \mathrm{~cm}$ as a safety margin.

An anterior-external approach carrying the path of the initial biopsy was performed. The detachment of the quadriceps muscle from the vastus lateralis enabled us to resect the tumor and to perform the femoral cut, while placing a counter-bend along the internal margin of the femur. During the placement of the massive knee prosthesis we controlled limb length, patellar stroke as well as knee mobility (Figure 3-5).

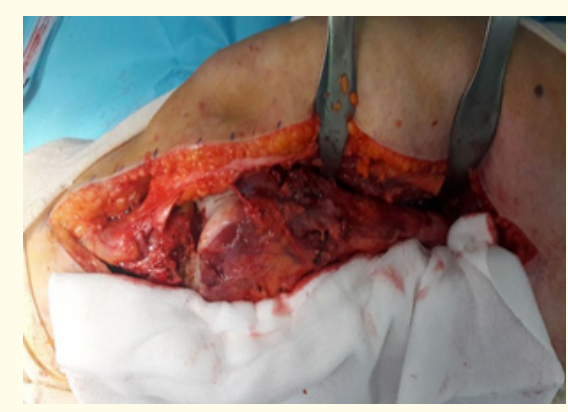

Figure 3: An anterior-external approach.

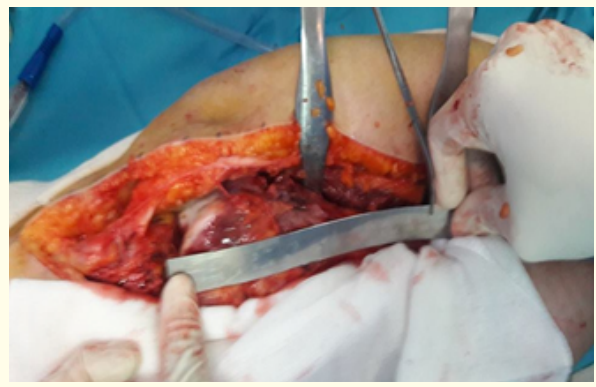

Figure 4: Intraoperative measurement used to estimate the size of the prosthesis to be used. 


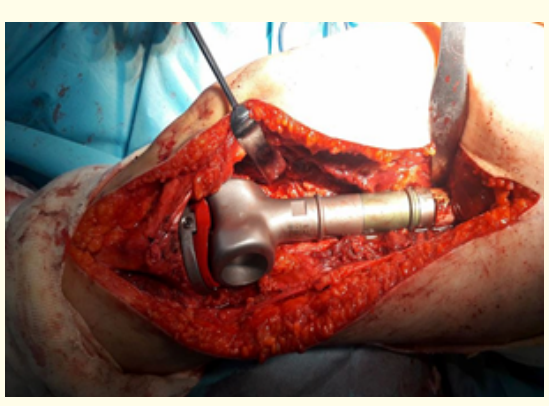

Figure 5: Endoprosthetic replacement of the distal femur.

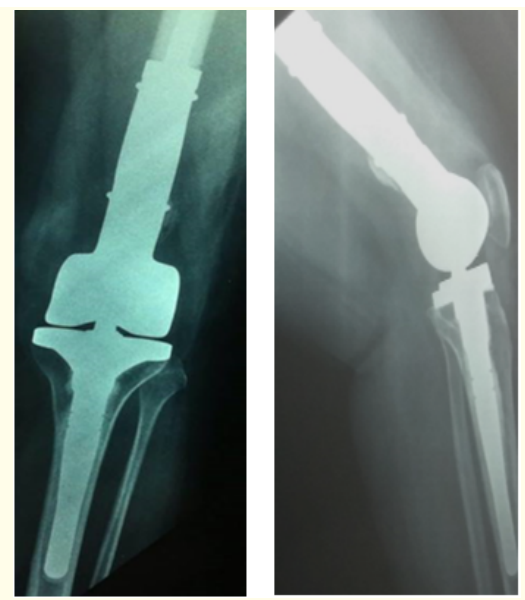

Figure 6: Post-operative radiographs

(Anteroposterior and lateral view).

On follow-up after 1 year, patient had a good knee mobility ( $0^{\circ}$ of extension, $100^{\circ}$ of flexion) and no inequality of the lower limbs length. There was no evidence of secondary infection, aseptic loosening or peri prosthetic fracture.

\section{Discussion}

The World Health Organization has classified GCT as an aggressive, potentially malignant lesion [4]. The surgical treatment of this tumor has always been controversial, with the desired treatment being a balance between adequate removal and retention of function [5].

A variety of treatment modalities are available for GCT, they range from intralesional curettage to wide resection with suitable reconstruction.
Intralesional excision leaves microscopic disease in the bone and the recurrence rate was reported as $60 \%$. Use of modern instruments such as high power burr, pulsatile jet lavage system, headlamp and dental mirror combined with multiple angled curettes to identify and access small pockets of residual disease didn't provide $100 \%$ results. Therefore, many investigators apply chemical (such as zinc chloride, carbolic acid and liquid nitrogen) and physical (such as high-speed burr) methods for destruction of any bone tumor in the cavity wall in order to reduce the local recurrence rate. Despite this, recurrence has been reported with the use of adjuvants [6,7]. However, when there is pathologic fracture, tumor recurrence, extensive destruction of the bone cortex, or insufficient solidity to meet the physical load after tumor excision, en bloc resection of tumor and reconstructive surgery of the bone defect need to be performed [8]. In our case, en bloc resection has been indicated for the two main reasons which are cortical destruction and extra osseous extend of the tumor with involvement of joint space.

There are various approaches to reconstruct the defects resulting from tumor resection. They include autograft, allograft and prosthetic replacement. Autograft can be used to feel the defect, but its quantity is limited and harvesting autograft causes donor site morbidity. Allograft is expensive and requires a bone bank. Allograft itself can lead to infection, fracture, non-union and joint instability [9].

Recently published articles show that the short-term outcome of prosthetic replacement for the treatment of GCT is satisfactory.

Prosthetic replacement has become the method of choice after bone tumor resection. It provides immediate restoration of bone stability, allowing the patients to start using the limb earlier, in addition to least rates of recurrence and complications [10]. The possible complications include secondary infection, aseptic loosening and breakage [11]. In our presentation we used a hinge massive prosthesis with good functional outcome.

\section{Conclusion}

Resection and knee arthroplasty is technically feasible and easy, it allows both to regulate the carcinological problem and to preserve articular function. However, it should be reserved for certain situations such as pathological fracture, tumor with extensive de- 
struction of the bone structure or difficulty in reconstruction after intralesional curettage. In the other cases, conservative treatment is the preferred method.

\section{Competing Interests}

The authors declare no competing interest.

\section{Authors' Contributions}

All the authors have contributed to this manuscript in ways that comply to ICMJE authorship criteria. All the authors have read and approved the final version of the manuscript.

\section{Bibliography}

1. Beldini N., et al. "Giant cell tumor of bone". Journal of Bone and Joint Surgery. American Volume 69.1 (1987): 106-114.

2. Bertoni F., et al. "Giant-cell tumor of bone with pulmonary metastases. Six case reports and a review of the literature". Clinical Orthopaedics and Related Research 237 (1988): 275-285.

3. Myers GJ., et al. "Endoprosthetic replacement of the distal femur for bone tumours: long-term results". Journal of Bone and Joint Surgery. British Volume 89.4 (2007): 521-526.

4. Szendroi M. "Giant-cell tumour of bone". Journal of Bone and Joint Surgery. British Volume 86.1 (2004): 5-12.

5. Wang HC., et al. "Management of grade III giant cell tumors of bones”. Journal of Surgical Oncology 92.1 (2005): 46-51.

6. McGrath PJ. "Giant-cell tumour of bone: An analysis of fiftytwo cases". Journal of Bone and Joint Surgery. British Volume 54.2 (1972): 216-229.

7. Kawai A., et al. "Relationship between magnitude of resection, complication, and prosthetic survival after prosthetic knee reconstructions for distal femoral tumors". Journal of Surgical Oncology 70.2 (1999): 109-115.

8. Yang ZM., et al. "The choice strategy of surgical treatment for giant cell tumor close to the knee (Chin)". Zhonghua Wai Ke Za Zhi 44.24 (2006): 1693-1698.

9. Gitelis S., et al. "Intralesional excision compared with en bloc resection for giant-cell tumors of bone". Journal of Bone and Joint Surgery. American Volume 75.11 (1993): 1648-1655.
10. Myers GJ., et al. "Endoprosthetic replacement of the distal femur for bone tumours: long-term results". Journal of Bone and Joint Surgery. British Volume 89.4 (2007): 521-526.

11. Maruthainar K., et al. "Massive endoprostheses for giant cell tumours of the distal femur: a 12-year follow-up". Knee 13.5 (2006): 378-381.

\section{Assets from publication with us}

- Prompt Acknowledgement after receiving the article

- Thorough Double blinded peer review

- Rapid Publication

- Issue of Publication Certificate

- High visibility of your Published work

Website: www.actascientific.com/

Submit Article: www.actascientific.com/submission.php

Email us: editor@actascientific.com

Contact uS: +919182824667 